BMJ Open Respiratory Research

\title{
Implications of using the GLI-2012, GOLD and Australian COPD-X recommendations in assessing the severity of airflow limitation on spirometry among an Indigenous population with COPD: an Indigenous Australians perspective study
}

\author{
Subash S Heraganahally (D) , , ${ }^{1,2}$ Timothy P Howarth (D) , ${ }^{3,4}$ Elisha White, ${ }^{1}$ \\ Helmi Ben Saad (1) 5,6
}

To cite: Heraganahally SS, Howarth TP, White E, et al. Implications of using the GLI2012, GOLD and Australian COPD-X recommendations in assessing the severity of airflow limitation on spirometry among an Indigenous population with COPD: an Indigenous Australians perspective study. BMJ Open Resp Res 2021;8:e001135. doi:10.1136/ bmjresp-2021-001135

- Additional supplemental material is published online only. To view, please visit the journal online (http://dx.doi. org/10.1136/bmjresp-2021001135).

Received 31 October 2021 Accepted 6 December 2021

\footnotetext{
A) Check for updates

(C) Author(s) (or their employer(s)) 2021. Re-use permitted under CC BY-NC. No commercial re-use. See rights and permissions. Published by BMJ.

For numbered affiliations see end of article.
}

Correspondence to Dr Subash S Heraganahally; hssubhashcmc@hotmail.com

\section{ABSTRACT}

Background Assessment of airflow limitation (AFL) is crucial in the clinical evaluation of patients with chronic obstructive pulmonary disease (COPD). However, in the absence of normative reference values among adult Australian Indigenous population, the implications of utilising the Global Lung Function Initiative (GLI-2012), Global Initiative for Chronic Obstructive Lung Disease (GOLD) and the Australian concise COPD-X recommended severity classifications is not known. Moreover, spirometry values (forced vital capacity (FVC) and forced expiratory volume in $1 \mathrm{~s}\left(\mathrm{FEV}_{1}\right)$ ) are observed to be $20 \%-30 \%$ lower in an apparently healthy Indigenous population in comparison to Caucasian counterparts.

Methods Adult Indigenous patients diagnosed to have COPD on spirometry (postbronchodilator (BD) FEV I FVC $<0.7$ ((GOLD, (COPD-X)) and slower limit of normal (others/mixed reference equations) for GLI-2012) were assessed for AFL severity classifications on Post-BD FEV values (mild, moderate, severe, very severe) as per the recommended classifications.

Results From a total of 742 unique patient records of Indigenous Australians, 253 were identified to have COPD via GOLD/COPD-X criteria ( $\mathrm{n}=238$ ) or GLI-2012 criteria $(\mathrm{n}=238)$ with significant agreeance between criteria (96\%, $\kappa=0.901)$. Of these, the majority were classified as having moderate or severe/very-severe AFL with significant variability across classification criteria (COPD-X (40\%-43\%), GOLD (33\%-65\%), GLI-2012 (18\%-75\%)). The FVC and $\mathrm{FEV}_{1}$ values also varied significantly between classification criterion (COPD-X/GOLD/GLI-2012) within the same AFL category, with COPD-X 'moderate' AFL almost matching 'severe' AFL categorisation by GOLD or GLI2012.

Conclusions Health professionals caring for Indigenous patients with COPD should be aware of the clinical implications and consequences of utilising various recommended AFL classifications in the absence of validated spirometry reference norms among adult Indigenous patients.

\begin{abstract}
Key messages
In the absence of established lung function reference norms for adult Indigenous population, how will the airflow limitation severity classification on spirometry would display among Indigenous Australian patient with chronic obstructive pulmonary disease (COPD) by applying the global lung function initiative (GLI)-2012, global initiative for chronic obstructive lung disease (GOLD) and COPD-X recommendations?

- Majority of Indigenous Australian patients with COPD will likely fall into either the 'severe' or 'very severe' category irrespective of which of the three (COPD-X GOLD, GLI) recommended lung function severity classifications used.

- Health professionals caring for Indigenous patients with COPD should be made aware of potential consequences when adopting spirometry airflow limitation severity classifications, established in non-Indigenous populations that may have overall management and therapeutic implications.
\end{abstract}

\section{INTRODUCTION}

Chronic obstructive pulmonary disease (COPD) is one of the leading causes of morbidity and mortality among the Aboriginal and Torres Straits Islander populations of Australia (henceforth respectfully referred to as Indigenous Australians or Indigenous people or patients), with a much higher prevalence reported in the Northern Territory (NT) Indigenous population. ${ }^{2}{ }^{2}$ Moreover, hospital admission rates are also reported to be significantly higher for the adult Indigenous patients and COPD is one of the potentially preventable causes of admissions 
in this population. ${ }^{3}{ }^{4}$ Emerging evidence in the literature suggests that Indigenous Australians not only have a higher prevalence of COPD, but also tend to exhibit other concurrent pulmonary conditions, in particular the presence of bronchiectasis, ${ }^{5-11}$ along with significantly lower lung function parameters (LFPs) in comparison to their non-Indigenous counterparts. ${ }^{12-14}$

In the clinical assessment of patients presenting with symptoms of COPD, the lung function tests/spirometry play an integral role in the diagnosis, assessment of severity of airflow limitation (AFL) and in guiding therapeutic interventions. ${ }^{15-17}$ However, lung function norms are yet to be established for the adult Indigenous population. The limited available evidence in the literature suggests that Indigenous Australians may have up to $20 \%-30 \%$ lower values for forced vital capacity (FVC) and forced expiratory volume in $1 \mathrm{~s}\left(\mathrm{FEV}_{1}\right)$ in comparison to Australian Caucasians. ${ }^{12} 131819$ Furthermore, although the Global Lung Function Initiative (GLI-2012) spirometric reference norms ${ }^{20}$ are shown to fit various ethnic groups including the general adult Australian population, ${ }^{21}$ due to lack of Indigenous Australians representation in the GLI-2012 contemporary adult Australian data, it is unclear if the GLI-2012 data fit the adult Indigenous Australian population. Recently, smaller studies have demonstrated that the GLI-2012 norms may not be appropriate for the Australian Indigenous adults regardless of which ethnicity option is selected, including 'others/mixed'. ${ }^{132}$ Yet, the current recommendations are to use GLI-2012 'others/mixed' equations among the adult Indigenous Australians, Torres Strait Islanders, New Zealand Māori and Pacific Island populations. ${ }^{23}$

Several well-established recommendations, including the global strategy for the diagnosis, management, and prevention of COPD (global initiative for chronic obstructive lung disease (GOLD)), have been developed for the purpose of classifying the severity of AFL among patients with COPD (GOLD 1 to 4 ) by spirometry in the overall holistic management. ${ }^{24}$ In the Australian context, the concise tool for COPD-X is the recommended/advocated tool that is widely adopted in assessing the severity of AFL by spirometry in order to facilitate in the stepwise management of patients with COPD. ${ }^{25}{ }^{26}$ The COPD-X guidelines have also been endorsed by the Royal Australian College of General Practitioners for use at the primary healthcare level. ${ }^{25-27}$

Nevertheless, the implications of utilising these recommended spirometry parameters in assessing/classifying the severity of AFL among Indigenous Australians have not been investigated. Moreover, the spirometry cut-off values to assess the severity of AFL differ between the two recommendations (ie, 'GOLD' vs 'COPD-X'). Therefore, the adoption of either of these tools in assessing the severity of AFL among Indigenous patients with COPD may have differing implications due to the following three reasons. First, Indigenous Australian adults appear to have up to $20 \%-30 \%$ lower values for $\mathrm{FEV}_{1}$ in comparison to Australian Caucasians. ${ }^{12}{ }^{13}$ Second, there are no well-established spirometry norms for the adult Indigenous population, and thus reference is made against the Caucasian population. ${ }^{232}$ Finally, there is a higher prevalence of COPD and COPD/Bronchiectasis among Indigenous Australians. ${ }^{10}{ }^{11}$ Taking into consideration these aforementioned factors, it is inevitable that the severity of COPD, in terms of AFL, will be either under or overestimated, or potentially lead to misclassification of COPD stages, which in turn may have significant implications on the short and long term management of COPD among Indigenous patients.

Hence, it may be important to evaluate the relevance/ implications of applying the GLI-2012, GOLD and COPD-X recommendations to an Indigenous Australian population and assess how the spirometry parameters (namely $\mathrm{FEV}_{1}$ and $\mathrm{FEV}_{1} / \mathrm{FVC}$ ) may display among patients with a clinical diagnosis of COPD. Therefore, this study endeavours to investigate the relevance and implications of AFL severity classifications in an Australian Indigenous population diagnosed to have COPD in the Top End Health Service (TEHS) region of the NT of Australia.

\section{POPULATION AND METHODS \\ Setting and ethics}

This study was conducted at the Respiratory and Sleep service based at the Royal Darwin hospital/Darwin respiratory and sleep health/Darwin private hospital in the TEHS region of the NT of Australia. In the NT, approximately $30 \%$ of the population self-identify as Indigenous Australian, the highest proportion compared with all other Australian states and territories. ${ }^{29}$

The study participants included in this study are inclusive of the data sets of participants from our previous reports assessing factors influencing and implications of chest radiological findings and LFPs in the adult Indigenous Australians residing in the Top End NT of Australia. ${ }^{1314} 3031$ This study was conducted and reported according to strengthening reporting of health research involving Indigenous people. ${ }^{32}$

\section{Patient and public involvement}

As the study was retrospective in nature, patients' participation or individual consent from the study participants was not required. In the public involvement perspective, local institute Indigenous Australian representatives were consulted in reviewing and approving this manuscript for its design, conduct, reporting, dissemination of our research work, in particular, the appropriateness and respect in relation to the Indigenous context represented in this study.

\section{Study participants and inclusion criteria}

The study participants included were Indigenous Australian patients residing in the TEHS region of the NT of Australia who had undergone spirometry testing 
between 2012 and 2020. Patients were referred for spirometry by primary health practitioners, respiratory specialist and other specialist physicians as a part of routine clinical care. A total of 1350 lung function tests were recorded by Indigenous patients during the study period, of which 965 met test acceptability criteria. This assessment only used the earliest recorded and acceptable for session quality lung function test of Indigenous patients, resulting in a total 742 tests available for analysis.

\section{Lung function testing}

All spirometry testing were performed according to the American thoracic and the European respiratory societies guidelines/recommendations, including calibration of equipment and quality assurance. ${ }^{33}$ The tests were performed via a portable single-breath diffusing capacity device 'EasyOne Pro, ndd Medical Technologies'. ${ }^{34}$ All volume-time and flow-volume graphs were individually assessed for acceptability for session quality. Only spirometric tests that were graded as acceptable for session quality were included in this study. More details are available from previous reports from our centre. ${ }^{135}$

When appropriate, all patients undergoing elective spirometry testing were instructed to refrain from smoking for at least 2-4 hours prior to spirometry testing and to avoid using airway directed inhaled pharmacotherapy during the preceding 6-12hours of spirometry testing, and among patients taking some forms of longer acting inhaled pharmacotherapy to avoid for 24 hours prior to testing. According to the GOLD criteria used in earlier burden of obstructive lung disease studies, bronchodilator (BD) responsiveness for spirometry parameters were assessed 15-20 min after inhalation of $400 \mu \mathrm{g}$ of salbutamol via a spacer. The presence of a clinically significant $\mathrm{BD}$ responsiveness was determined if there was a post-BD increase in $\mathrm{FEV}_{1}$ of $\geq 12 \%$ and $\geq 200 \mathrm{~mL}$ from the pre-BD FEV $1 .{ }^{1824}$ For the purpose of this study, only post-BD percent predicted values for $\mathrm{FEV}_{1}$ and $\mathrm{FEV}_{1} / \mathrm{FVC}$ ratio values were reported. In our centre, faced with the lack of specific spirometric norms for the adult Australian Indigenous population, the predicted values were calculated using the third National health and nutrition examination survey (NHANES) Caucasian reference sets ('other ethnicity') ${ }^{36}$ For comparison with GLI-2012, the dataset was run through the GLI-2012 dataset conversion app using 'others/mixed' reference ethnicity, with resultant lower limits of normal (LLN) and z-scores used throughout this study. If the study participants were identified to have undergone multiple LFTs during the study period, the earliest and acceptable test for session quality was utilised for analysis.

\section{COPD diagnosis}

To ascertain the presence of COPD, post-BD $\mathrm{FEV}_{1} / \mathrm{FVC}$ $<0.7$ was used for GOLD ${ }^{24}$ and COPD-X,,$^{25} 26$ and $\leq \mathrm{LLN}$ was used for GLI-2012. ${ }^{20}$

\section{COPD AFL severity assessment criteria}

Table 1 illustrates the COPD severity criteria's according to three international recommendations. In brief, for GLI-2012 four grading AFL severity (based on post-BD $\mathrm{FEV}_{1}$ z-scores) were used. ${ }^{37} 38$ For GOLD, four grading AFL severity (based on percentage predicted post-BD $\mathrm{FEV}_{1}$ values) were used. ${ }^{24}{ }^{38}$ For COPD-X, three grading AFL severity (based on the percentage predicted post-BD $\mathrm{FEV}_{1}$ values) were used. ${ }^{25}{ }^{26}$ Both GOLD and COPD-X used the NHANES Caucasian reference set for 'other ethnicity' in line with standard practice. ${ }^{36}$

\section{Clinical data collection}

As per standard protocol, patients' age (on the date of testing), sex, height, weight and body mass index (BMI, $\mathrm{kg} / \mathrm{m}^{2}$ ) were recorded. Smoking history, indication for spirometry and the patients' electronic medical records were reviewed to document the clinical diagnosis of

\begin{tabular}{|c|c|c|c|}
\hline Recommended tools & Severity categories & Post-BD FEV $/$ /FVC (absolute) & Post-BD FEV \\
\hline \multirow[t]{4}{*}{ GOLD $^{22}$} & Mild & $<0.7$ & $\geq 80 \%$ \\
\hline & Moderate & $<0.7$ & $50 \%-79 \%$ \\
\hline & Severe & $<0.7$ & $30 \%-79 \%$ \\
\hline & Very severe & $<0.7$ & $<30 \%$ \\
\hline \multirow[t]{3}{*}{ COPD- $\mathrm{X}^{2324}$} & Mild & $<0.7$ & $60 \%-79 \%$ \\
\hline & Moderate & $<0.7$ & $40 \%-59 \%$ \\
\hline & Severe & $<0.7$ & $<40 \%$ \\
\hline \multirow[t]{4}{*}{$\mathrm{GLL}^{37}$} & Mild & $\leq L L N$ & $z$-score $\geq-2$ \\
\hline & Moderate & $\leq L L N$ & $-2.0>-3.0$ \\
\hline & Severe & $\leq \mathrm{LLN}$ & $-3.0>-4.0$ \\
\hline & Very severe & $\leq \mathrm{LLN}$ & z-score $\leq-4.0$ \\
\hline
\end{tabular}

BD, bronchodilator; COPD, chronic obstructive pulmonary disease ; FEV 1 , forced expiratory volume in 1 s; FVC, forced vital capacity; GLI, global lung function imitative; GOLD, global initiative for chronic obstructive lung disease; LLN, lower limit of normal. 
COPD. The patient was noted as deceased if it was recorded in the medical records and no linkage to death register was undertaken.

\section{Statistical analysis}

Continuous parameters were tested for normality via the Shapiro-Wilks distribution test, with BMI and smoking pack-years the only parameters displaying a non-parametric distribution. Non-parametric parameters were presented as medians (IQR), normally distributed parameters as means (95\% CIs) and categorical parameters as numbers $(\%)$. Clinical characteristics were stratified by severity category and compared across classification guidelines (COPD-X vs GOLD vs GLI) using univariate linear regression for normally distributed parameters, quantile regression for non-parametric parameters and $\chi^{2}$ test for categorical parameters. Cohens' Kappa

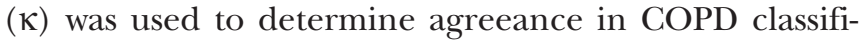
cation between GOLD/COPD-X methods and GLI-2012, and between these criteria and what was reported in the patients' medical records. LFPs were stratified by severity category and tested for equality across recommended classification via univariate linear regression. All data were analysed in STATA IC V.15 (StataCorp) and alpha was set to 0.05 throughout.

\section{RESULTS}

\section{Clinical data}

A total of 742 unique patient records were available for analysis, within which a total of 253 patients were identified to have COPD on spirometry, with significant agreeance between the two methods used $\left(\mathrm{FEV}_{1} /\right.$
FVC $<0.7$ ( $\mathrm{n}=238)$ or $\mathrm{FEV}_{1} / \mathrm{FVC} \leq \mathrm{LLN}(\mathrm{n}=238), \kappa=0.907$, agreement $96 \%$ ). Agreement between spirometry criterion and the clinical diagnosis of COPD as recorded in the medical records was significantly lower (GOLD/ COPD-X and medical record, $\kappa=0.44$, agreement $74 \%$ and GLI-2012 and medical record, $\kappa=0.407$, agreement $73 \%)$. The majority of patients $(51 \%)$ were male with a mean age 53.6 years (95\% CI 52.1 to 55.2 ), median BMI of $23.04 \mathrm{~kg} / \mathrm{m}^{2}$ (IQR 19.43-27.96) and a high prevalence of either current $(51 \%)$ or former $(40 \%)$ smokers with no significant differences between those identified with COPD via GOLD/COPD-X or GLI-2012 (table 2).

\section{Spirometry results}

Of the patients with COPD identified, the proportion categorised as severe/very severe was significantly higher using the GLI-2012 criteria (table 3). Patients in the GLI2012 'very severe' category were significantly younger than patients in the 'severe' or 'very severe' categories according to COPD-X and GOLD (table 4). Distribution of BMI and smoking status did not differ across AFL severity categories. Although overall the prevalence of deceased patients was similar between COPD-X/ GOLD/GLI-2012, (16\% ( $\mathrm{n}=38), 16 \% \quad(\mathrm{n}=38)$, and $15 \%$ $(n=35)$, respectively), the distribution of mortality across AFL severity categories significantly differed. Of the 38 deceased in COPD-X/GOLD classification, $31 \%$ were in the mild or moderate category according to COPD-X and $16 \%$ according to GOLD, whereas of the 35 deceased according to GLI-2012 classification, $12 \%$ were in the mild or moderate severity categories (table 3 ).

\begin{tabular}{|c|c|c|c|}
\hline Variables & Clinical parameters & $\mathrm{n}=\mathbf{2 3 8}$ & $n=238$ \\
\hline Age & Years (mean $(95 \% \mathrm{Cl}))$ & 54.67 (53.13 to 56.2$)$ & 52.69 (51.15 to 54.23$)$ \\
\hline \multirow[t]{4}{*}{ Corpulence data and status } & BMI (median (IQR)) & $22.86(19.38-27.89)$ & $22.91(19.04-27.89)$ \\
\hline & Normal weight (BMI 18.5-24.9kg/m²) & $99(42 \%)$ & $95(40 \%)$ \\
\hline & Overweight (BMI 25-29.9kg/m²) & $50(21 \%)$ & $49(21 \%)$ \\
\hline & Obese $\left(\mathrm{BMI} \geq 30 \mathrm{~kg} / \mathrm{m}^{2}\right)$ & $40(17 \%)$ & $42(18 \%)$ \\
\hline \multirow[t]{2}{*}{ Smoking status } & Never smoker & $20(8 \%)$ & $17(7 \%)$ \\
\hline & Former smoker & 95 (40\%) & $98(41 \%)$ \\
\hline Mortality & Deceased age (years) (mean $(95 \% \mathrm{Cl}))$ & 57.79 (53.97 to 61.61$)$ & 57.15 (53.08 to 61.22$)$ \\
\hline COPD & Clinical history of COPD & $161(70 \%)$ & $156(68 \%)$ \\
\hline
\end{tabular}

Fifteen patients were identified via $\mathrm{FEV}_{1} / \mathrm{FVC}<0.7$ who were not identified via $\mathrm{FEV}_{1} / \mathrm{FVC}<\mathrm{LLN}$, and vice versa 15 patients were identified via $\mathrm{FEV}_{1} /$ $\mathrm{FVC}>\mathrm{LLN}$ and not by $\mathrm{FEV}, \mathrm{FVC}<0.7$.

$\mathrm{BMI}$, body mass index; COPD, chronic obstructive pulmonary disease; $\mathrm{FEV}_{1}$, forced expiratory volume in $1 \mathrm{~s}$; FVC, forced vital capacity; GLI, global lung function imitative; GOLD, global initiative for chronic obstructive lung disease; LLN, lower-limit of normal. 
Table 3 Severity of COPD airflow limitation (AFL) and mortality within the three differing severity classifications

\begin{tabular}{lccc}
\hline $\begin{array}{l}\text { Severity of } \\
\text { COPD by AFL }\end{array}$ & $\begin{array}{l}\text { COPD-X } \\
(\mathbf{n}=238)^{*}\end{array}$ & $\begin{array}{l}\text { GOLD } \\
(\mathbf{n}=238)\end{array}$ & $\begin{array}{l}\text { GLI-2012 } \\
(\mathbf{n}=238)\end{array}$ \\
\hline Mild & $35(15 \%)$ & $5(2 \%)$ & $16(7 \%)$ \\
\hline Moderate & $96(40 \%)$ & $78(33 \%)$ & $43(18 \%)$ \\
\hline Severe & $102(43 \%)$ & $97(41 \%)$ & $83(35 \%)$ \\
\hline Very severe & - & $58(24 \%)$ & $96(40 \%)$ \\
\hline Mortality (all & $\begin{array}{l}\text { COPD-X } \\
\text { cause) }\end{array}$ & $\begin{array}{l}\text { GOLD } \\
(\mathbf{n}=38)\end{array}$ & $\begin{array}{l}\text { GLI-2012 } \\
(\mathbf{n}=35)\end{array}$ \\
\hline Mild & $2(5 \%)$ & $0(0 \%)$ & $1(3 \%)$ \\
\hline Moderate & $10(26 \%)$ & $6(16 \%)$ & $3(9 \%)$ \\
\hline Severe & $26(68 \%)$ & $15(39 \%)$ & $10(29 \%)$ \\
Very severe & - & $17(45 \%)$ & $21(60 \%)$ \\
\hline
\end{tabular}

${ }^{*}$ Five patients had $\mathrm{FEV}_{1}>80 \%$ which are unclassified according to COPD-X criteria.

COPD, chronic obstructive pulmonary disease; COPD-X, concise tool for chronic obstructive pulmonary disease; $F E V_{1}$, forced expiratory volume in $1 \mathrm{~s}$; GLI, global lung initiative; GOLD, global initiative for chronic obstructive lung disease.

\section{Spirometry parameters according to different recommended classifications}

Spirometry parameters differed significantly within severity categories across the three recommended classifications (table 5, figure 1). Z-scores of post-BD FVC and $\mathrm{FEV}_{1}$ were on average one unit lower using COPD-X recommendation for each of the mild, moderate and severe categories compared with both GOLD and GLI2012 categorisation and for $\mathrm{FEV}_{1} / \mathrm{FVC}$ in the severe category. Absolute and percentage predicted values for LFPs were significantly lower across all severity categories when using the COPD-X classification. GOLD and GLI2012 classifications showed significant overlap of mean LFPs in both the mild and moderate categories; however, in the severe and very severe categories GOLD values were significantly lower. A separate analysis of moderate COPD-X against severe GLI-2012 and GOLD showed that for the majority of LFPs moderate COPD-X did not significantly differ from severe GLI-2012 classification (online supplemental appendix 1).

\section{DISCUSSION}

To the best of the authors' knowledge, this is the first study to demonstrate the clinical implications of classifying severity of AFL by adopting various spirometry COPD severity criterion in an Indigenous population with COPD, especially from the NT of Australia. This study has highlighted that irrespective of which of the three recommended AFL classifications used (COPD-X, GOLD, GLI) $(<0.7, \leq \mathrm{LLN})$, most Indigenous patients with COPD who are referred for lung function testing in a specialist centre, will likely fall into either the 'severe' or 'very severe' category. Moreover, the FVC and FEV values vary significantly between the three recommended severity classification criteria's.
Spirometry parameters are crucial in day-to-day clinical practice, not only for the accurate diagnosis and classifying the severity of AFL, but also in the management of COPD with airway directed inhaled pharmacotherapy. ${ }^{25-27}$ While it is possible the high prevalence of 'severe' AFL categorisation among Indigenous Australian patients with COPD accurately represents the severity of the underlying disease as noted in this study, it is also plausible that these high rates of 'severe' categorisation are an artefact of the use of reference values drawn from non-Indigenous populations. ${ }^{28}$ The Australian COPD-X tool provides stepwise recommendations for the use of airway directed inhaled pharmacotherapy, such as short-acting BD, short-acting muscarinic antagonists, long-acting $\beta$-agonists, long-acting muscarinic antagonists, and inhaled corticosteroids (ICS) as per the severity assessed on spirometry criteria. ${ }^{25}{ }^{26} \mathrm{In}$ the current study, most patients (83\%) would be classified to have either moderate or severe COPD, and therefore, are likely to be considered prescribed with ICS containing inhaled pharmacotherapy. Among the Indigenous Australian population, however, particularly in the NT, comorbid bronchiectasis and COPD is highly prevalent, ${ }^{7-11}$ and results in typically worse spirometric patterns compared with Indigenous patients with COPD in isolation. ${ }^{30}$ In the current study out of the 253 patients with COPD identified by spirometry, $56(22 \%)$ had radiological evidence of concomitant bronchiectasis. Furthermore, a recent study from our centre has shown significantly higher rates of excessive yearly $\mathrm{FEV}_{1}$ decline among Indigenous patients on ICS, which may be due to higher prevalence of comorbid bronchiectasis. ${ }^{31}$ Thus, the use of the COPD-X tool in this setting with no validated reference values along with higher prevalence of rather complex and concomitant respiratory comorbidities ${ }^{11}$ has the potential to result in overprescription of ICS, which could be detrimental to patients outcomes.

Worldwide the burden of COPD is noted to be increasingly prevalent across various ethnic and socioeconomic groups. ${ }^{39}$ This is also indeed true for Indigenous populations, especially among those living in high-income countries ${ }^{40}$ such as the First Nation Indigenous people of the $\mathrm{USA}^{41}$ and Canada, ${ }^{42}{ }^{43}$ Indigenous Australians ${ }^{8}$ and New Zealand Māori. ${ }^{40}$ Despite evidence in the literature suggesting that adult Indigenous people have lower spirometry values compared with their non-Indigenous counterparts, ${ }^{12-14}$ including a report by de Hamel and Glass $^{44}$ dating back to 1975 comparing LFPs among New Zealand Māori and people of European descent, there appears to be an unprecedented gap in developing guidelines and recommendations in classifying AFL in the overall management COPD among Indigenous people globally. Although there is continued debate regarding which reference norms to use in specific populations, ${ }^{45-47}$ in the Australian context it is recommended to use GLI-2012 'others/mixed' reference norms for the adult Indigenous population. ${ }^{23}$

This study has demonstrated the potential effects of using these recommendations ${ }^{23-26}$ for the classification of 


\begin{tabular}{|c|c|c|c|c|c|}
\hline COPD-X* & & Mild $(n=35)$ & Moderate $(n=96)$ & Severe $(n=102)$ & Very severe \\
\hline Sex & Male & $18(51 \%)$ & $49(51 \%)$ & 57 (56\%) & - \\
\hline Age & Years (mean $(95 \% \mathrm{CI}))$ & 57.11 (53.01 to 61.21$)$ & 56.12 (53.51 to 58.74$)$ & 52.59 (50.53 to 54.65$)$ & - \\
\hline BMI & $\mathrm{kg} / \mathrm{m}^{2}$ (median (IQR)) & $24.54(19.53-28.35)$ & 24.64 (20.94-29.66) & $21.19(17.06-24.84)$ & - \\
\hline \multirow{4}{*}{$\begin{array}{l}\text { Smoking } \\
\text { status }\end{array}$} & Never smoker & $1(3 \%)$ & $12(13 \%)$ & $5(5 \%)$ & - \\
\hline & Former smoker & $10(29 \%)$ & $41(43 \%)$ & $43(42 \%)$ & - \\
\hline & Current smoker & $24(69 \%)$ & $43(45 \%)$ & $54(53 \%)$ & - \\
\hline & $\begin{array}{l}\text { Smoking pack years } \\
\text { (median (IQR)) }\end{array}$ & $30(15.5-43.75)$ & $12.5(5.38-40)$ & 26.35 (11.13-39.38) & - \\
\hline COPD & Clinical history of COPD & $25(71 \%)$ & $59(64 \%)$ & $76(77 \%)$ & - \\
\hline \multirow[t]{2}{*}{ Mortality } & Deceased (all cause) & $2(6 \%)$ & $10(10 \%)$ & $26(25 \%)$ & - \\
\hline & $\begin{array}{l}\text { Deceased age (years) } \\
\text { (mean }(95 \% \mathrm{Cl}))\end{array}$ & 62.39 to 75.3 & 65.27 (57.02 to 73.52$)$ & 54.07 (49.98 to 58.15$)$ & - \\
\hline GOLD & & Mild $(n=5)$ & Moderate $(n=78)$ & Severe $(n=97)$ & Very severe $(n=58)$ \\
\hline Sex & Male & $3(60 \%)$ & $41(53 \%)$ & $52(54 \%)$ & $31(53 \%)$ \\
\hline Age & Years (mean $(95 \% \mathrm{CI}))$ & 52.02 (27.88 to 76.17$)$ & 55.94 (53.14 to 58.74$)$ & 55.88 (53.43 to 58.32$)$ & 51.16 (48.53 to 53.78$)$ \\
\hline BMI & $\mathrm{kg} / \mathrm{m}^{2}$ (median (IQR)) & $27.6(22.27-38.57)$ & $24.5(20.28-28.35)$ & 23.28 (19.08-28.97) & $21.74(17.01-24.54)$ \\
\hline \multirow{4}{*}{$\begin{array}{l}\text { Smoking } \\
\text { status }\end{array}$} & Never smoker & $2(40 \%)$ & $8(10 \%)$ & $7(7 \%)$ & $3(5 \%)$ \\
\hline & Former smoker & $1(20 \%)$ & $22(28 \%)$ & $47(48 \%)$ & $25(43 \%)$ \\
\hline & Current smoker & $2(40 \%)$ & $48(62 \%)$ & $43(44 \%)$ & $30(52 \%)$ \\
\hline & $\begin{array}{l}\text { Smoking pack years } \\
\text { (median (IQR)) }\end{array}$ & $11.25(4.5-112.5)$ & $23(8-45)$ & $18(5.1-37.5)$ & $27.5(14.7-38.75)$ \\
\hline COPD & Clinical history of COPD & $1(20 \%)$ & $50(64 \%)$ & $66(70 \%)$ & $44(76 \%)$ \\
\hline \multirow[t]{2}{*}{ Mortality } & Deceased (all cause) & $0(0 \%)$ & $6(8 \%)$ & $15(15 \%)$ & $17(29 \%)$ \\
\hline & $\begin{array}{l}\text { Deceased age (years) } \\
(\text { mean }(95 \% \mathrm{Cl}))\end{array}$ & & 66.05 (52.67 to 79.42 ) & 62.54 (57.19 to 67.9$)$ & 50.69 (46.1 to 55.28$)$ \\
\hline GLI-2012 & & Mild $(n=16)$ & Moderate $(n=43)$ & Severe $(n=83)$ & Very severe $(n=96)$ \\
\hline Sex & Male & $9(56 \%)$ & $19(44 \%)$ & $44(53 \%)$ & $51(53 \%)$ \\
\hline Age & Years (mean $(95 \% \mathrm{Cl}))$ & 55.41 (47.52 to 63.29$)$ & 57.85 (53.86 to 61.83$)$ & 54.53 (51.98 to 57.07$)$ & 48.35 (46.31 to 50.39$)$ \\
\hline BMI & $\mathrm{kg} / \mathrm{m}^{2}$ (median (IQR)) & $23.64(21.2-27.8)$ & $24.54(20.2-28.98)$ & 23.99 (19.61-29.02) & $22.03(17.21-25.81)$ \\
\hline \multirow{4}{*}{$\begin{array}{l}\text { Smoking } \\
\text { status }\end{array}$} & Never smoker & $2(13 \%)$ & $3(7 \%)$ & $6(7 \%)$ & $6(6 \%)$ \\
\hline & Former smoker & $4(25 \%)$ & $18(42 \%)$ & $37(45 \%)$ & $39(41 \%)$ \\
\hline & Current smoker & $10(63 \%)$ & $22(51 \%)$ & $40(48 \%)$ & $51(53 \%)$ \\
\hline & $\begin{array}{l}\text { Smoking pack years } \\
\text { (median (IQR)) }\end{array}$ & $33(11.25-60)$ & $21(8-37.5)$ & $12.5(5-40)$ & $20(7-37.5)$ \\
\hline COPD & Clinical history of COPD & $8(50 \%)$ & $32(74 \%)$ & $50(62 \%)$ & $66(72 \%)$ \\
\hline \multirow{2}{*}{$\begin{array}{l}\text { Mortality (all } \\
\text { cause) }\end{array}$} & Deceased (all cause) & $1(6 \%)$ & $3(7 \%)$ & $10(12 \%)$ & $21(22 \%)$ \\
\hline & $\begin{array}{l}\text { Deceased age (years) } \\
(\text { mean }(95 \% \mathrm{Cl}))\end{array}$ & 75.3 & $62.15,62.39$ to 85.35 & 64.12 (57.43 to 70.8 ) & 51.14 (47.11 to 55.18$)$ \\
\hline
\end{tabular}

${ }^{*}$ Five patients excluded from COPD-X as $\mathrm{FEV}_{1}$ was $>80 \%$.

$\mathrm{BMI}$, body mass index; COPD, chronic obstructive pulmonary disease; COPD-X, concise tool for chronic obstructive pulmonary disease; FEV , forced expiratory volume in $1 \mathrm{~s}$; GLI, global lung function initiative; GOLD, global initiative for chronic obstructive lung disease.

AFL severity among NT Australian Indigenous patients with COPD. We observed that $75 \%$ of patients would be classified to have 'severe' or 'very severe' AFL by adopting these recommended criterion. It was outside the scope of this study to assess AFL categorisation alongside patients' subjective experience of the disease, however, given the study sample is drawn from a referred population one may expect skewing towards the moderate/severe categories. Although the GLI-2012 categorisation does not recommend specific treatment/management options based on AFL category, the primary care provider is likely to be heavily influenced by this and may consider different treatment options if a patient is noted to have 'severe' or 'very severe' AFL compared with 'mild/moderate'. Underdiagnosis or overdiagnosis of COPD is not uncommon in clinical practice even in non-Indigenous patients, including misclassification and inappropriate use of airway directed inhaled pharmacotherapy. ${ }^{48-51}$ In this study, we observed that the agreement between clinical diagnosis of COPD as per medical records entry 


\begin{tabular}{|c|c|c|c|c|}
\hline Mild & COPD-X (n=35) & GOLD $(n=5)$ & GLI-2012 (n=16) & P value \\
\hline FVC post-BD (L) & $2.98(2.72,3.24)$ & $4.08(2.67,5.48)$ & $3.5(2.96,4.03)$ & $0.034^{*}$ \\
\hline FVC post-BD (\%) & $79.51(74.24,84.79)$ & $107.8(88.78,126.82)$ & $93.19(85.31,101.06)$ & $0.003^{*}$ \\
\hline FVC post-BD (z) & $-1.09(-1.31,-0.86)$ & $1.18(-0.28,2.64)$ & $0.07(-0.52,0.66)$ & $<0.001^{\star}$ \\
\hline $\mathrm{FEV}_{1}$ post-BD (L) & $1.94(1.77,2.12)$ & $2.76(1.86,3.66)$ & $2.32(1.94,2.69)$ & $0.024^{*}$ \\
\hline FEV 1 post-BD (\%) & $67.63(65.77,69.49)$ & $92.6(77.53,107.67)$ & $78.63(71.78,85.47)$ & $<0.001^{*}$ \\
\hline FEV ${ }_{1}$ post-BD $(\mathrm{z})$ & $-2.06(-2.24,-1.88)$ & $-0.23(-1.18,0.73)$ & $-1.17(-1.59,-0.75)$ & $<0.001^{*}$ \\
\hline $\mathrm{FEV}_{1} / \mathrm{FVC}$ post-BD (AV) & $0.64(0.62,0.66)$ & $0.68(0.65,0.7)$ & $0.64(0.61,0.68)$ & 0.644 \\
\hline $\mathrm{FEV}_{1} / \mathrm{FVC}$ post-BD (\%) & $83(80.48,85.52)$ & $85.6(79.29,91.91)$ & $84.38(80.51,88.24)$ & 0.479 \\
\hline $\mathrm{FEV}_{1} /$ FVC post-BD (z) & $-2.34(-2.57,-2.1)$ & $-1.91(-2.53,-1.29)$ & $-2.3(-2.62,-1.98)$ & 0.737 \\
\hline Moderate & COPD-X $(n=96)$ & GOLD $(n=78)$ & GLI-2012 (n=43) & \\
\hline FVC post-BD (L) & $2.3(2.16,2.43)$ & $2.75(2.58,2.91)$ & $2.61(2.39,2.83)$ & 0.002 \\
\hline FVC post-BD (\%) & $62.61(60.67,64.56)$ & $72.97(70.01,75.94)$ & $73.49(70.64,76.34)$ & $<0.001^{*}$ \\
\hline FVC post-BD (z) & $-2.54(-2.69,-2.38)$ & $-1.66(-1.84,-1.47)$ & $-1.66(-1.81,-1.5)$ & $<0.001^{*}$ \\
\hline $\mathrm{FEV}_{1}$ post-BD (L) & $1.4(1.31,1.48)$ & $1.75(1.64,1.85)$ & $1.66(1.5,1.82)$ & $<0.001^{*}$ \\
\hline FEV ${ }_{1}$ post-BD (\%) & $48.46(47.39,49.53)$ & $59.83(57.99,61.68)$ & $59.12(56.79,61.44)$ & $<0.001^{*}$ \\
\hline FEV $_{1}$ post-BD (z) & $-3.32(-3.42,-3.21)$ & $-2.57(-2.72,-2.43)$ & $-2.54(-2.64,-2.45)$ & $<0.001^{*}$ \\
\hline $\mathrm{FEV}_{1} /$ FVC post-BD (AV) & $0.61(0.59,0.62)$ & $0.63(0.62,0.64)$ & $0.62(0.6,0.65)$ & 0.111 \\
\hline $\mathrm{FEV}_{1} /$ FVC post-BD (\%) & $76.91(74.37,79.44)$ & $80.23(77.46,83.01)$ & $80.47(78.04,82.89)$ & 0.054 \\
\hline $\mathrm{FEV}_{1} /$ FVC post-BD (z) & $-2.68(-2.85,-2.5)$ & $-2.43(-2.59,-2.27)$ & $-2.43(-2.63,-2.23)$ & $0.042^{*}$ \\
\hline Severe & COPD-X $(n=102)$ & GOLD (n=97) & GLI-2012 (n=83) & \\
\hline FVC post-BD (L) & $1.74(1.64,1.83)$ & $2.03(1.92,2.14)$ & $2.31(2.16,2.45)$ & $<0.001^{*}$ \\
\hline FVC post-BD (\%) & $45.95(43.79,48.11)$ & $55.8(53.96,57.65)$ & $60(57.39,62.61)$ & $<0.001^{\star}$ \\
\hline FVC post-BD (z) & $-4.06(-4.26,-3.86)$ & $-3.14(-3.31,-2.98)$ & $-2.71(-2.86,-2.56)$ & $<0.001^{*}$ \\
\hline $\mathrm{FEV}_{1}$ post-BD (L) & $0.85(0.8,0.9)$ & $1.15(1.08,1.21)$ & $1.37(1.28,1.47)$ & $<0.001^{\star}$ \\
\hline FEV ${ }_{1}$ post-BD (\%) & $28.27(26.87,29.68)$ & $39.99(38.86,41.12)$ & $45.1(43.13,47.06)$ & $<0.001^{*}$ \\
\hline $\mathrm{FEV}_{1}$ post-BD $(\mathrm{z})$ & $-4.67(-4.8,-4.54)$ & $-3.87(-3.98,-3.75)$ & $-3.49(-3.56,-3.42)$ & $<0.001^{*}$ \\
\hline $\mathrm{FEV}_{1} / \mathrm{FVC}$ post-BD (AV) & $0.5(0.48,0.52)$ & $0.57(0.55,0.59)$ & $0.59(0.58,0.61)$ & $<0.001^{*}$ \\
\hline $\mathrm{FEV}_{1} / \mathrm{FVC}$ post-BD (\%) & $61.85(59.28,64.43)$ & $72.38(70.21,74.55)$ & $73.72(70.41,77.04)$ & $<0.001^{*}$ \\
\hline FEV $_{1} /$ FVC post-BD (z) & $-3.95(-4.13,-3.78)$ & $-3.13(-3.32,-2.95)$ & $-2.88(-3.05,-2.71)$ & $<0.001^{*}$ \\
\hline Very severe & COPD-X & GOLD $(n=58)$ & GLI-2012 (n=96) & \\
\hline FVC post-BD (L) & & $1.57(1.45,1.68)$ & $1.75(1.65,1.85)$ & $0.024^{*}$ \\
\hline FVC post- BD (\%) & & $40.97(38.29,43.64)$ & $46.79(44.59,48.99)$ & $0.001^{*}$ \\
\hline FVC post-BD (z) & & $-4.51(-4.75,-4.27)$ & $-4.19(-4.38,-4.01)$ & $0.040^{*}$ \\
\hline FEV ${ }_{1}$ post-BD (L) & & $0.72(0.66,0.77)$ & $0.89(0.82,0.96)$ & $<0.001^{*}$ \\
\hline $\mathrm{FEV}_{1}$ post-BD (\%) & & $23.4(22,24.79)$ & $29.41(27.73,31.09)$ & $<0.001^{*}$ \\
\hline FEV $_{1}$ post-BD (z) & & $-5.02(-5.16,-4.88)$ & $-4.8(-4.91,-4.69)$ & $0.015^{\star}$ \\
\hline $\mathrm{FEV}_{1} / \mathrm{FVC}$ post-BD (AV) & & $0.47(0.44,0.49)$ & $0.51(0.49,0.53)$ & $0.012^{*}$ \\
\hline $\mathrm{FEV}_{1} / \mathrm{FVC}$ post-BD (\%) & & $57.21(53.66,60.75)$ & $63.11(60.56,65.67)$ & $0.007^{*}$ \\
\hline $\mathrm{FEV}_{1} /$ FVC post-BD (z) & & $-4.28(-4.5,-4.06)$ & $-3.94(-4.14,-3.74)$ & $0.027^{*}$ \\
\hline
\end{tabular}

*Statistically significant.

$\mathrm{AV}$, absolute value; BD, bronchodilator; COPD, chronic obstructive pulmonary disease; COPD-X, concise tool for chronic obstructive pulmonary disease; $\mathrm{FEV}_{1}$, forced expiratory volume in $1 \mathrm{~s}$; FVC, forced vital capacity; GLI, global lung initiative; GOLD, global initiative for chronic obstructive lung disease; Z, z-score.

against spirometry criteria was only about $54 \%$. It is not clear, given the fact that Indigenous patients have a higher prevalence of smoking and respiratory conditions, ${ }^{78}$ if health practitioners may have a preconceived perception that any or all Indigenous patients presenting with respiratory symptoms will have COPD. This further emphasises the desperate need to advocate for clinical, spirometric diagnostic and severity criteria classification, and management guidelines for COPD among the Indigenous Australian population.

The authors do acknowledge that there are only a limited number of spirometry studies available which 

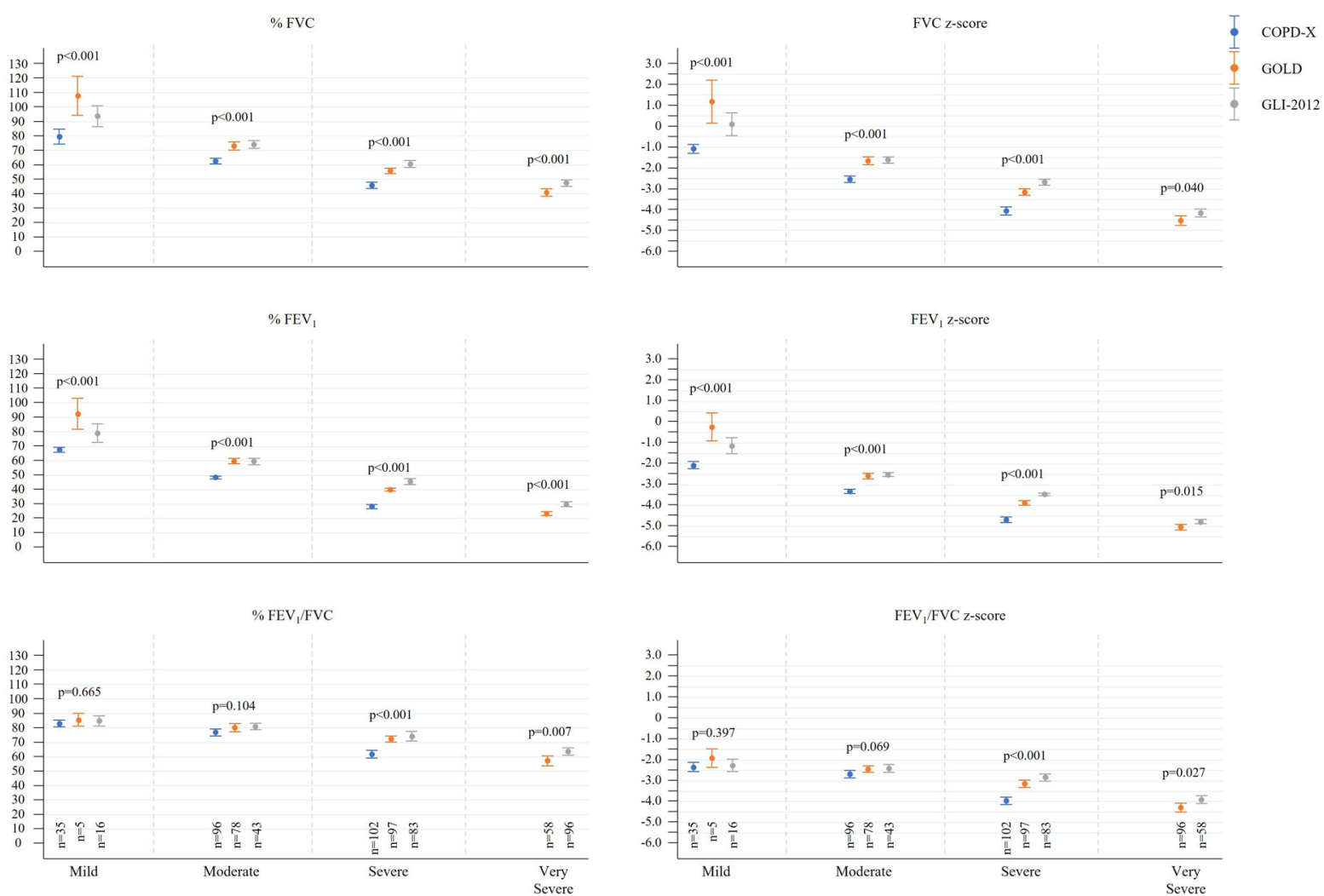

Figure 1 Means (95\% Cls) of percentage predicted values and Z-scores for postbronchodilator values by airflow limitation severity category with $p$ values obtained via ANOVA. ANOVA, analysis of variance; COPD-X, concise tool for chronic

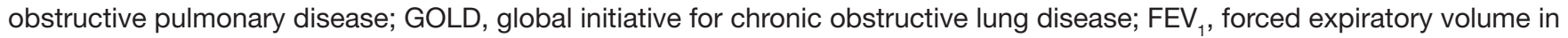
$1 \mathrm{~s} ;$ FVC, forced vital capacity; GLI, global lung function initiative.

have included Indigenous population, and that these studies may be subject to biases in participant recruitment. ${ }^{12-14} 18192230313552-59$ It is also important to acknowledge that smoking rates and pre-existing lung conditions are also highly prevalent in this population, hence recruiting study participants without smoking history or pre-existing lung disease imposes substantial challenges to conduct adult spirometry studies in an Indigenous population. Moreover, a significant proportion of Indigenous people live in regional and remote settings. Previous recommendations have suggested the use of approximate conversion factors when utilising European references sets for other ethnic groups (ie, Hong Kong Chinese 1.0; Polynesian 0.9; North Indian and Pakistani 0.9; Japanese American 0.89; South Indian and African descent 0.87$){ }^{60}$

As mentioned above, the limited data available in the literature suggest that the Australian Indigenous population could have up to $20 \%$ to $30 \%$ lower values for FVC and $\mathrm{FEV}_{1}$ values compared with the Australian Caucasians. ${ }^{12}{ }^{13}$ Hence, it may be very reasonable to be inquisitive to know if such correctional factors could also be appropriate in this Indigenous population. Although we did not include this aspect in our main study outcome, we did create a subanalysis applying an arbitrary inflation of $15 \%$ to $\mathrm{FVC}$ and $\mathrm{FEV}_{1}$ values (on the basis of previous research in this population demonstrating FVC and $\mathrm{FEV}_{1}$ values consistently $15 \%-20 \%$ lower than Caucasian patients ${ }^{12} 131819$ in order to understand how the AFL severity classification would be effected with this correction factor applied (online supplemental appendix 2). In this model, instead of 238 patients being identified with COPD by $\mathrm{FEV}_{1} / \mathrm{FVC}<0.7$ and $\mathrm{FEV}_{1} / \mathrm{FVC}<\mathrm{LLN}$, respectively, only 197 patients fit these criteria. Furthermore, we observed that by COPD-X and GOLD categorisation, most individuals ( $81 \%$ and $67 \%$, respectively) will be re-categorised to either mild or moderate AFL; a much closer approximation of AFL severity distributions observed in non-Indigenous populations. Under 'mild' and 'moderate' AFL categorisation post-BD, LFPs significant differed between patients categorised according to COPD-X, GOLD or GLI-2012. LFPs according to COPD-X AFL categorisation were consistently one severity step removed from GOLD and GLI-2012 - that is, 'mild' under COPD-X better matched 'moderate' under GOLD or GLI-2012, and 'moderate' under COPD-X better matched 'severe' under GOLD or GLI-2012. Stakeholders, relevant organisations, such as Australian and New Zealand Society of Respiratory Science and policy-makers should consider taking into consideration of the available evidence, including realistic limitations and challenges and attempt to incorporate AFL/COPD severity classification, including considering correctional factors, to aid in the overall management of COPD in 
this underprivileged Indigenous population. Moreover, in the authors view, health professionals caring for Indigenous patients with COPD should be made aware of potential consequences when adopting existing spirometry AFL classifications, established in non-Indigenous populations. Indeed, the context of pulmonary disease among Indigenous Australians is more similar to that of Asian populations than Caucasian populations. Including a high prevalence of concomitant chronic lung disease alongside COPD, in particular the presence of bronchiectasis. The position statement of the Asian Pacific Society of Respirology suggests cautious use of ICS in their population. ${ }^{61}$

Our study, for the first time, has highlighted the impact of adopting particular AFL criterion for the Australian NT Indigenous population with COPD. Hence, this study is of significant clinical relevance in addressing and highlighting this importance of COPD severity classification and the use of spirometry reference ranges among Indigenous patients with COPD. Health professionals, especially primary health practitioners in regional and rural/ remote communities caring for Indigenous patients, should be aware of potential implications in classifying AFL severity for clinical decision making, in particular, in the Australian context while using COPD-X recommendations. This study also highlights the importance for healthcare providers for Indigenous people not swapping between various COPD severity classifications which would lead to inconsistencies. Moreover, it is also vital to understand that reference values and guidelines developed for other ethnic populations, including Caucasians cannot be considered as 'norm' for Indigenous people and the approach to the holistic management of COPD should be different to their Caucasian counterpart. As such, spirometry plays an integral role in the diagnosis, quantifying the severity, and management of COPD with inhaled pharmacotherapy according to the severity classification. ${ }^{62}$ Although significant progress has been made towards prevention and management of COPD in Australia $^{64}$ and globally, within the Indigenous Australian population the problem still remains - more specifically, in relation to establishing COPD diagnosis/severity classification and management guidelines. Further dedicated efforts are required to close the respiratory health gap in our Indigenous population, ${ }^{65}$ not only in reducing COPD related morbidity and mortality, but also in reducing healthcare cost and utilisation.

\section{Limitations}

The results of this study are restricted to the Australian Indigenous study participants from the TEHS region of the NT of Australia and the outcomes represented in this study may or may not be applicable to other Indigenous populations globally. Moreover, in the lack of similar studies in other non-Australian Indigenous cohort we were unable to compare if our study outcomes compare to other Indigenous populations. Nevertheless, this is the first ever study to provide insight into the implications of utilising the established AFL classifications in an Indigenous population, and we anticipate this study will be of interest and be influential among researchers globally to address these important issues for their respective Indigenous populations. The authors are not aware of any updated AFL/COPD recommendations or guidelines in any Indigenous population globally at the time of writing of this paper. Other potential limitations that may or may not be relevant specifically to this current study are described in our previously published reports. ${ }^{13143031}$

\section{CONCLUSION}

Irrespective of which of the three recommended AFL classifications used (COPD-X, GOLD, GLI-2012), most Indigenous patients with COPD referred for lung function testing will likely fall into either the severe or very severe category. Spirometry values for FVC and FEV vary significantly between the three recommended criteria. In the absence of established spirometry reference norms among the adult Indigenous population, health professionals should be aware of implications in using various recommended AFL classifications in the overall management of Indigenous patients presenting with COPD, including, prescribing inhaled pharmacotherapy.

Author affiliations

${ }^{1}$ Department of Respiratory and Sleep Medicine, Royal Darwin Hospital, Darwin, Northern Territory, Australia

${ }^{2}$ College of Medicine and Public Health, Flinders University, Adelaide, South Australia, Australia

${ }^{3}$ College of Health and Human Sciences, Charles Darwin University, Casuarina, Northern Territory, Australia

${ }^{4}$ Respiratory and Sleep Health, Darwin Private Hospital, Darwin, Northern Territory, Australia

${ }^{5}$ Laboratory of Physiology, Faculty of Medicine of Sousse, University of Sousse, Sousse, Tunisia

${ }^{6}$ Research laboratory "Heart failure, LR12SP09", Farhat HACHED Hospital, University of Sousse, Sousse, Tunisia

Acknowledgements We sincerely thank all the respiratory technologists and Respiratory Clinical Nurse Consultants from Darwin Respiratory and Sleep health and Royal Darwin Hospital, Darwin Private Hospital, Darwin, Australia, for facilitating and performing lung function testing for Indigenous study participants living in the remote and regional Indigenous communities during respiratory outreach visits. We thank Mr. Xinlin Jing, Health Information Services, Royal Darwin Hospital, Darwin, Northern Territory, Australia for helping with data collection for this study. We also extend our sincere appreciation to our Indigenous health workers, especially to Mr Izaak Thomas (Australian Indigenous Luritja descendent) from the respiratory chronic respiratory disease co-ordination division in reviewing and approving this manuscript for the appropriateness of the representation and respect in relation to the Indigenous context represented in this study.

Contributors All authors made substantial contributions to conception and design, acquisition of data, or analysis and interpretation of data; took part in drafting the article or revising it critically for important intellectual content; agreed to submit to the current journal; gave final approval of the version to be published; and agree to be accountable for all aspects of the work. The guarantor SH accepts full responsibility for the work and/or the conduct of the study, had access to the data, and controlled the decision to publish.

Funding The authors have not declared a specific grant for this research from any funding agency in the public, commercial or not-for-profit sectors.

Competing interests None declared.

Patient consent for publication Not applicable. 
Ethics approval The study was approved by the Human Research Ethics Committee of the NT, TEHS and Menzies School of Health Research (Reference no: HREC 20193445).

Provenance and peer review Not commissioned; externally peer reviewed. Data availlability statement Not applicable.

Supplemental material This content has been supplied by the author(s). It has not been vetted by BMJ Publishing Group Limited (BMJ) and may not have been peer-reviewed. Any opinions or recommendations discussed are solely those of the author(s) and are not endorsed by BMJ. BMJ disclaims all liability and responsibility arising from any reliance placed on the content. Where the content includes any translated material, BMJ does not warrant the accuracy and reliability of the translations (including but not limited to local regulations, clinical guidelines, terminology, drug names and drug dosages), and is not responsible for any error and/or omissions arising from translation and adaptation or otherwise.

Open access This is an open access article distributed in accordance with the Creative Commons Attribution Non Commercial (CC BY-NC 4.0) license, which permits others to distribute, remix, adapt, build upon this work non-commercially, and license their derivative works on different terms, provided the original work is properly cited, appropriate credit is given, any changes made indicated, and the use is non-commercial. See: http://creativecommons.org/licenses/by-nc/4.0/.

ORCID iDs

Subash S Heraganahally http://orcid.org/0000-0003-0788-7137

Timothy P Howarth http://orcid.org/0000-0003-3028-0376

Helmi Ben Saad http://orcid.org/0000-0002-7477-2965

\section{REFERENCES}

1 Leading causes of mortality. Australian Institute of health and welfare 2020. Aboriginal and Torres Strait Islander health performance framework 2020 summary report. cat. No. IHPF 2. Canberra: AlHW. Available: https://www.indigenoushpf.gov.au/publications/hpfsummary-2020 [Accessed 5 Jul 2021].

2 Australian Institute of Health and Welfare (AlHW). Aboriginal and Torres Strait Islander health performance framework 2017 report: Northern Territory. Available: https://www.aihw.gov.au/getmedia/ 0e60dc3c-a582-4b7f-a4d1-1e623a91745e/aihw-ihw-186-2017-hpfnt.pdf.aspx? inline=true [Accessed Sep 2021].

3 Jayakody A, Oldmeadow C, Carey M, et al. Frequent avoidable admissions amongst Aboriginal and non-Aboriginal people with chronic conditions in New South Wales, Australia: a historical cohort study. BMC Health Serv Res 2020;20:1082.

4 Australian Institute of Health and Welfare 2020. Disparities in potentially preventable hospitalisations across Australia: exploring the data. cat. No. HPF 51. Canberra: AlHW. Available: https://www. aihw.gov.au/reports/primary-health-care/disparities-inpotentiallypreventable-hospitalisations-exploring-the-data [Accessed 23 Apr 2020].

5 Heraganahally SS, Silva SAMS, Howarth TP, et al. Comparison of clinical manifestation among Australian Indigenous and nonIndigenous patients presenting with pleural effusion. Intern Med J 2021.

6 Heraganahally SS, Mortimer N, Howarth T, et al. Utility and outcomes among Indigenous and non-Indigenous patients requiring domiciliary oxygen therapy in the regional and rural Australian population. Aust $J$ Rural Health 202110.1111/ajr.12782. [Epub ahead of print: 13 Sep 2021]

7 Kruavit A, Fox M, Pearson R, et al. Chronic respiratory disease in the regional and remote population of the Northern Territory top end: a perspective from the specialist respiratory outreach service. Aust $J$ Rural Health 2017;25:275-84.

8 Heraganahally SS, Wasgewatta SL, McNamara K, et al. Chronic obstructive pulmonary disease in Aboriginal patients of The Northern Territory of Australia: a landscape perspective. Int J Chron Obstruct Pulmon Dis 2019;14:2205-17.

9 Heraganahally SS, Wasgewatta SL, McNamara K, et al. Chronic obstructive pulmonary disease with and without bronchiectasis in Aboriginal Australians - a comparative study. Intern Med $J$ 2020;50:1505-13.

10 Mehra S, Chang A, Lam C, et al. Bronchiectasis among Australian Aboriginal and non-Aboriginal patients in the regional and remote population of the Northern Territory of Australia. Rural Remote Health 2021;21:6390.

11 Heraganahally SS, Howarth TP, Sorger L. Chest computed tomography findings among adult Indigenous Australians in the Northern Territory of Australia. J Med Imaging Radiat Oncol 2021;14.
12 Veale AJ, Peat JK, Salome CM, et al. 'Normal' lung function in rural Australian Aborigines*. Aust N Z J Med 1997;27:543-9.

13 Heraganahally SS, Howarth T, White E, et al. Lung function parameters among Australian Aboriginal 'apparently healthy' adults: an Australian Caucasian and Global Lung Function Initiative (GLI2012) various ethnic norms comparative study. Expert Rev Respir Med 2021;15:833-43.

14 Howarth T, Saad HB, Perez AJ, et al. Comparison of diffusing capacity of carbon monoxide (DLCO) and total lung capacity (TLC) between Indigenous Australians and Australian Caucasian adults. PLoS One 2021;16:e0248900.

15 Ranu H, Wilde M, Madden B. Pulmonary function tests. Ulster Med J 2011;80:84-90.

16 Liang BM, Lam DC, Feng YL. Clinical applications of lung function tests: a revisit. Respirology 2012;17:611-9.

17 Johnson JD, Theurer WM. A stepwise approach to the interpretation of pulmonary function tests. Am Fam Physician 2014;89:359-66.

18 Cooksley NAJB, Atkinson D, Marks GB, et al. Prevalence of airflow obstruction and reduced forced vital capacity in an Aboriginal Australian population: the cross-sectional BOLD study. Respirology 2015;20:766-74.

19 Hall GL, Pearson G. Reduced forced vital capacity in Aboriginal Australians: biology or missing evidence? Respirology 2015;20:693-4

20 Quanjer PH, Stanojevic S, Cole TJ, et al. Multi-Ethnic reference values for spirometry for the 3-95-yr age range: the global lung function 2012 equations. Eur Respir J 2012;40:1324-43.

21 Hall GL, Thompson BR, Stanojevic S, et al. The global lung initiative 2012 reference values reflect contemporary Australasian spirometry. Respirology 2012;17:1150-1.

22 White E, James A, de Klerk N. Selection of appropriate spirometry reference values in Aboriginal Australians. Australian Indigenous Health Bulletin 2019;19.

23 Brazzale D, Hall G, Swanney MP. Reference values for spirometry and their use in test interpretation: a position statement from the Australian and New Zealand Society of respiratory science. Respirology 2016;21:1201-9.

24 Global initiative for chronic obstructive lung disease. Global strategy for the diagnosis, management, and prevention of chronic obstructive pulmonary disease, 2021. Available: http://www. goldcopd.org [Accessed Jul 2021].

25 Yang IA, George J, Jenkins S. The COPD-X plan: Australian and New Zealand guidelines for the management of chronic obstructive pulmonary disease 2021.COPD guidelines Committee - version 2. 63, 2021. Available: https://copdx.org.au [Accessed 5 Jul 2021].

26 Dabscheck E, McDonald CF, Yang IA. Concise guidance for COPD. Respirology 2020;25:1129-32.

27 Walters J. COPD Diagnosis, management and the role of the GP. Aust Fam Physician 2010;39:100-3.

28 Blake TL, Chang AB, Petsky HL, et al. Spirometry reference values in Indigenous Australians: a systematic review. Medical J Aust 2016;205:35-40.

29 Australian bureau of statistics. Estimates of Aboriginal and Torres Strait Islander Australians. ABS, Canberra, Australia, 2016.

30 Heraganahally SS, Howarth T, Mo L, et al. Critical analysis of Spirometric patterns in correlation to chest computed tomography among adult Indigenous Australians with chronic airway diseases. Expert Rev Respir Med 2021;15:1229-38.

31 Heraganahally SS, Ponneri TR, Howarth TP, et al. The effects of inhaled airway directed pharmacotherapy on decline in lung function parameters among Indigenous Australian adults with and without underlying airway disease. Int J Chron Obstruct Pulmon Dis 2021;16:2707-20.

32 National Health and Medical Research Council. Ethical conduct in research with Aboriginal and Torres Strait Islander peoples and communities: guidelines for researchers and stakeholders. Canberra: Commonwealth of Australia, 2018.

33 Miller MR, Hankinson J, Brusasco V, et al. Standardisation of spirometry. Eur Respir J 2005:26:319-38.

34 ndd medical technologies, 2017. EasyOne Pro®. Available: https:// www.ndd.ch/en/product/easyone-pro.html [Accessed 5 Jul 2021].

35 Schubert J, Kruavit A, Mehra S, et al. Prevalence and nature of lung function abnormalities among Indigenous Australians referred to specialist respiratory outreach clinics in the Northern Territory. Intern Med J 2019;49:217-24.

36 Hankinson JL, Odencrantz JR, Fedan KB. Spirometric reference values from a sample of the general U.S. population. Am J Respir Crit Care Med 1999;159:179-87.

37 Quanjer PH, Pretto JJ, Brazzale DJ, et al. Grading the severity of airways obstruction: new wine in new bottles. Eur Respir $J$ 2014;43:505-12. 
38 Anane I, Guezguez F, Knaz H, et al. How to stage airflow limitation in stable chronic obstructive pulmonary disease male patients? Am J Mens Health 2020:14:155798832092263.

39 Burney P, Patel J, Minelli C, et al. Prevalence and population attributable risk for chronic airflow obstruction in a large multinational study. Am J Respir Crit Care Med 2020

40 Ospina MB, Voaklander DC, Stickland MK, et al. Prevalence of asthma and chronic obstructive pulmonary disease in Aboriginal and non-Aboriginal populations: a systematic review and meta-analysis of epidemiological studies. Can Respir J 2012;19:355-60.

41 Laffey KG, Nelson AD, Laffey MJ, et al. Chronic respiratory disease disparity between American Indian/Alaska native and white populations, 2011-2018. BMC Public Health 2021;21:1466.

42 Ospina MB, Voaklander D, Senthilselvan A, et al. Incidence and prevalence of chronic obstructive pulmonary disease among Aboriginal peoples in Alberta, Canada. PLoS One 2015; $10:$ e0123204.

43 Bird Y, Moraros J, Mahmood R, et al. Prevalence and associated factors of COPD among Aboriginal peoples in Canada: a cross-sectional study. Int J Chron Obstruct Pulmon Dis 2017; 12:1915-22.

44 de Hamel FA, Glass WJ. Observations on Maori-European lung function differences. Aust N Z J Med 1975;5:44-8.

45 Linares-Perdomo O, Hegewald M, Collingridge DS, et al. Comparison of NHANES III and ERS/GLI 12 for airway obstruction classification and severity. Eur Respir J 2016;48:133-41.

46 Huprikar NA, Holley AB, Skabelund AJ, et al. A comparison of global lung initiative 2012 with third National health and nutrition examination survey spirometry reference values. Implications in defining obstruction. Ann Am Thorac Soc 2019;16:225-30.

47 Brazzale DJ, Hall GL, Pretto JJ. Effects of adopting the new global lung function initiative 2012 reference equations on the interpretation of spirometry. Respiration 2013;86:183-9.

48 Johns DP, Walters JAE, Walters EH. Diagnosis and early detection of COPD using spirometry. J Thorac Dis 2014;6:1557-69.

49 Walters JA, Walters EH, Nelson M, et al. Factors associated with misdiagnosis of COPD in primary care. Prim Care Respir $J$ 2011:20:396-402

50 Petrie K, Toelle BG, Wood-Baker R, et al. Undiagnosed and misdiagnosed chronic obstructive pulmonary disease: data from the BOLD Australia study. Int J Chron Obstruct Pulmon Dis 2021;16:467-75.

51 Josephs $L$, Culliford $D$, Johnson $M$, et al. COPD overdiagnosis in primary care: a UK observational study of consistency of airflow obstruction. NPJ Prim Care Respir Med 2019;29:33.
52 Thompson JE, Sleigh AC, Passey ME, et al. Ventilatory standards for clinically well Aboriginal adults. Med J Aust 1992;156:566-9.

53 Bremner PR, de Klerk NH, Ryan GF, et al. Respiratory symptoms and lung function in aborigines from tropical Western Australia. Am J Respir Crit Care Med 1998;158:1724-9.

54 Verheijden MW, Ton A, James AL, et al. Respiratory morbidity and lung function in two Aboriginal communities in Western Australia. Respirology 2002;7:247-53.

55 Musk AW (Bill), James AL, Palmer LJ, et al. Respiratory infections and lung function in an Australian Aboriginal community. Respirology 2008;13:257-62.

56 Fenton ME, Graham BL, Stanojevic S, et al. Interpretation of spirometry in Saskatchewan first nations adults. Ann Am Thorac Soc 2018;15:1237-9.

57 Soltanifar M, Karunanayake C, Khadka D. Is a body shape index (ABSI) predictive of lung function? Int $J$ Respir Pulm Med 2019;6:101

58 Blake TL, Chang AB, Chatfield MD, et al. Global Lung Function Initiative-2012 'other/mixed' spirometry reference equation provides the best overall fit for Australian Aboriginal and/or Torres Strait Islander children and young adults. Respirology 2020;25:281-8.

59 Collaro AJ, Chang AB, Marchant JM, et al. Determinants and followup of lung function data from a predominantly first nations cohort of adults referred to specialist respiratory outreach clinics in regional and remote Queensland. Lung 2021;199:417-25.

60 Quanjer PH, Tammeling GJ, Cotes JE, et al. Lung volumes and forced ventilatory flows. Report Working Party standardization of lung function tests, European community for steel and coal. official statement of the European respiratory Society. Eur Respir J Suppl 1993;16:5-40.

61 Rhee CK, Chau NQ, Yunus F, et al. Management of COPD in Asia: a position statement of the Asian Pacific Society of Respirology. Respirology 2019;24:1018-25.

62 Bailey KL. The importance of the assessment of pulmonary function in COPD. Med Clin North Am 2012;96:745-52.

63 Ben Saad H. Interpretation of respiratory functional explorations of deficiency and incapacity in adult. Tunis Med 2020;98:797-815

64 Dunt D, Doyle C. Signs of progress in the Australian post-2000 COPD experience, but some old problems remain. Int J Chron Obstruct Pulmon Dis 2012;7:357-66.

65 Closing the gap: Indigenous health campaign. Canberra: Australian human rights Commission; 2021. closing the gap in partnership: everyone enjoys long and healthy lives, 2021. Available: https:// www.closingthegap.gov.au/everyone-enjoys-long-and-healthy-lives [Accessed May 2021]. 